\title{
Experimental zinc deficiency in guinea-pigs: clinical signs and some haematological studies
}

\author{
By R. P. GUPTA, P. C. VERMA* AND R. K. PAUL GUPTA \\ Department of Veterinary Pathology, Haryana Agricultural University, Hissar-125 004, \\ India
}

(Received 9 January 1985 - Accepted 7 March 1985)

1. Thirty-three male, weanling guinea-pigs were divided into two groups. One group was fed on a zinc-deficient ( $\mathrm{ZnD})$ diet $(1.25 \mathrm{mg} \mathrm{Zn} / \mathrm{kg}$ diet) for $45 \mathrm{~d}$ and then divided into two subgroups: subgroup 1 continued on diet $\mathrm{ZnD}$ while subgroup 2 was fed on a $\mathrm{Zn}$-repleted diet $(100 \mathrm{mg} \mathrm{Zn} / \mathrm{kg}$ diet) for $15 \mathrm{~d}$. The second group was fed on a $\mathrm{Zn}$-adequate diet ( $50 \mathrm{mg} \mathrm{Zn/} \mathrm{kg}$ diet) for $60 \mathrm{~d}$.

2. $\mathrm{Zn}$ deficiency could be produced within $21 \mathrm{~d}$ as evidenced by clinical signs and reduction in serum $\mathrm{Zn}$ concentration.

3. Clinical signs exhibited were listlessness, scabby lesions on skin near the foot pads, mild alopecia and a reduction in body-weight gain. No effect was observed on food intake.

4. Significant decreases in packed cell volume and total leucocyte count from $48 \mathrm{~d}$ onwards accompanied by absolute lymphocytopenia and relative neutrophilia were observed.

5. Supplementation of $\mathrm{Zn}$ in the $\mathrm{Zn}$-repleted group resulted in marked, though incomplete, improvement with regard to serum $\mathrm{Zn}$ concentration, clinical signs and haematological changes.

Zinc has been shown to be an essential element for mammals and plays an indispensable role in a number of body functions. Natural cases of its deficiency in man and domestic animals have been encountered throughout the world (Underwood, 1977). McBean et al. (1972) and others (Alberts et al. 1977; Hsieh \& Navia, 1980; Gordon \& O'Dell, 1983) have reported clinical signs of $\mathrm{Zn}$ deficiency in guinea-pigs experimentally fed on a $\mathrm{Zn}$-deficient diet up to $20 \mathrm{~d}$. The only report (Gordon \& O'Dell, 1983) traced in the literature regarding haematological observations in $\mathrm{Zn}$-deficient guinea-pigs revealed no effect on packed cell volume (PCV). The present work was, therefore, undertaken to produce $\mathrm{Zn}$ deficiency in guinea-pigs and to study the clinical signs and some haematological indices. An attempt was also made to examine the response to $\mathrm{Zn}$ repletion with respect to the previously mentioned indices.

\section{MATERIALS AND METHODS}

Thirty-three male albino guinea-pigs (20-d-old) of an English breed, weighing about 170-275 g were obtained from the Disease-Free Small Animal House, Haryana Agricultural University, Hissar and divided into two main groups containing nineteen and fourteen animals with mean body-weights of 215.6 (SE 7.18) and 204.83 (SE 3.91) g respectively. These were fed ad lib. on a semi-synthetic basal diet (Hsieh \& Navia, 1980). The diet contained egg albumin powder, sucrose, starch, potassium acetate, agar, salt mixture, cellulose, choline chloride, magnesium oxide, vitamin mixture and arachis oil. Based on the high requirement of vitamin $C$ by guinea-pigs, ascorbic acid was added at the rate of $2 \mathrm{~g} / \mathrm{kg}$ diet, as reported by Navia \& Lopez (1973). To avoid loss of nutrients during storage, particularly ascorbic acid and other vitamins, the diets were prepared in different lots at fortnightly intervals and kept under refrigeration in closed plastic containers as suggested by Navia \& Lopez (1973). 


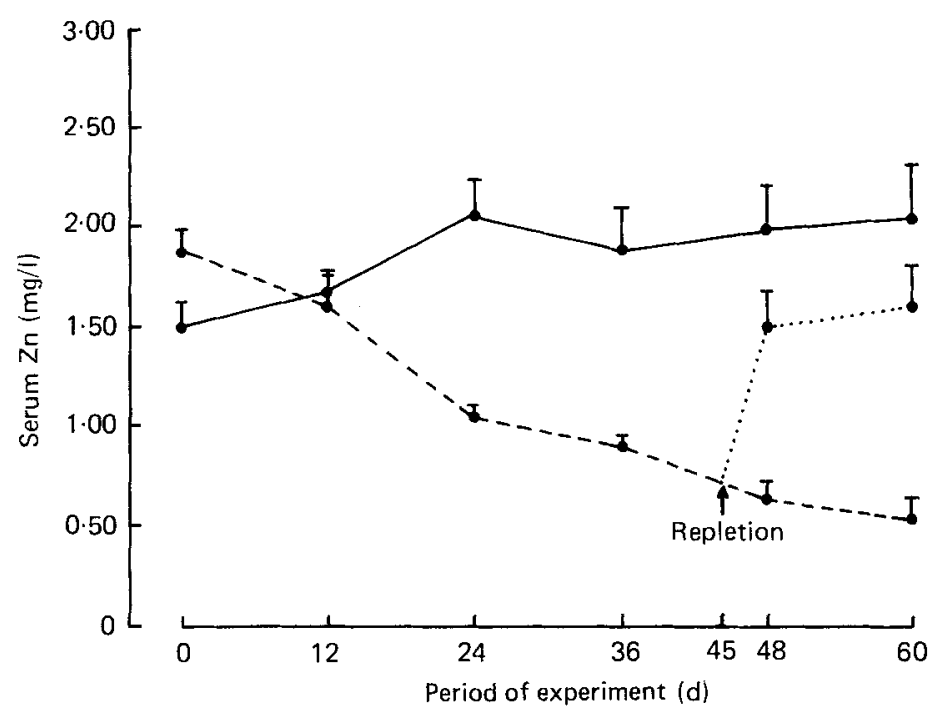

Fig. 1. Serum zinc concentration (mg/l) of $\mathrm{Zn}$-deficient (--), $\mathrm{Zn}$-replete $(.$.$) and control (-)$ guinea-pigs. Values are means with their standard errors represented by vertical bars.

Animals of one group were fed on a $\mathrm{Zn}$-deficient $(\mathrm{ZnD})$ diet containing 1.25 (SE 0.12) $\mathrm{mg}$ $\mathrm{Zn} / \mathrm{kg}$ for $45 \mathrm{~d}$ and then divided into two subgroups: animals of subgroup 1 (ten animals) were maintained on diet $\mathrm{ZnD}$, while animals of subgroup 2 (nine animals) were fed on a $\mathrm{Zn}$-repleted $(\mathrm{ZnR})$ diet $(100 \mathrm{mg} \mathrm{Zn} / \mathrm{kg})$ for $15 \mathrm{~d}$. All fourteen animals of the second group were fed on a $\mathrm{Zn}$-adequate control diet $(50 \mathrm{mg} \mathrm{Zn} / \mathrm{kg}$ ). All animals were kept individually in plastic cages and provided with double-distilled water ad lib. To avoid coprophagy, perforated acrylic sheets were fixed at the bottom of cages. Just before the start of the experiment, the cages, feeding dishes and water bottles were rinsed in EDTA solution $(10 \mathrm{~g} / 1 ; \mathrm{Zn}$-chelating agent) and then thoroughly washed with double-distilled water.

The animals were closely observed daily for clinical signs and weighed at weekly intervals up to the end of the experiment $(60 \mathrm{~d})$. Blood samples were taken from the heart at the start of the experiment and subsequently at 12-d intervals, and placed separately in vials containing EDTA $(10 \mathrm{~g} / \mathrm{l})$ and in sterilized tubes for serum separation. For differential leucocyte counts (DLC), smears were prepared from fresh blood and stained with Giemsa's stain.

Serum $\mathrm{Zn}$ concentration was estimated by atomic absorption spectrophotometry. PCV and total leucocyte counts (TLC) were determined using a microhaematocrit and improved Neubaur haemocytometer methods respectively (Schalm et al. 1975).

The statistical significance was assessed using Student's $t$ test.

RESULTS

Serum Zn concentration

Mean serum $\mathrm{Zn}$ concentrations of each group are illustrated in Fig. 1.

A statistically significant decrease $(P<0.01)$ was observed from $24 \mathrm{~d}$ onwards in serum $\mathrm{Zn}$ levels of the group given diet $\mathrm{ZnD}$ as compared with the control group. The group given $\operatorname{diet} \mathrm{ZnR}$ showed a rapid increase in serum $\mathrm{Zn}$ concentration within $3 \mathrm{~d}$ of repletion. Later, the rate of increase in $\mathrm{Zn}$ concentraion appeared to be very moderate. 


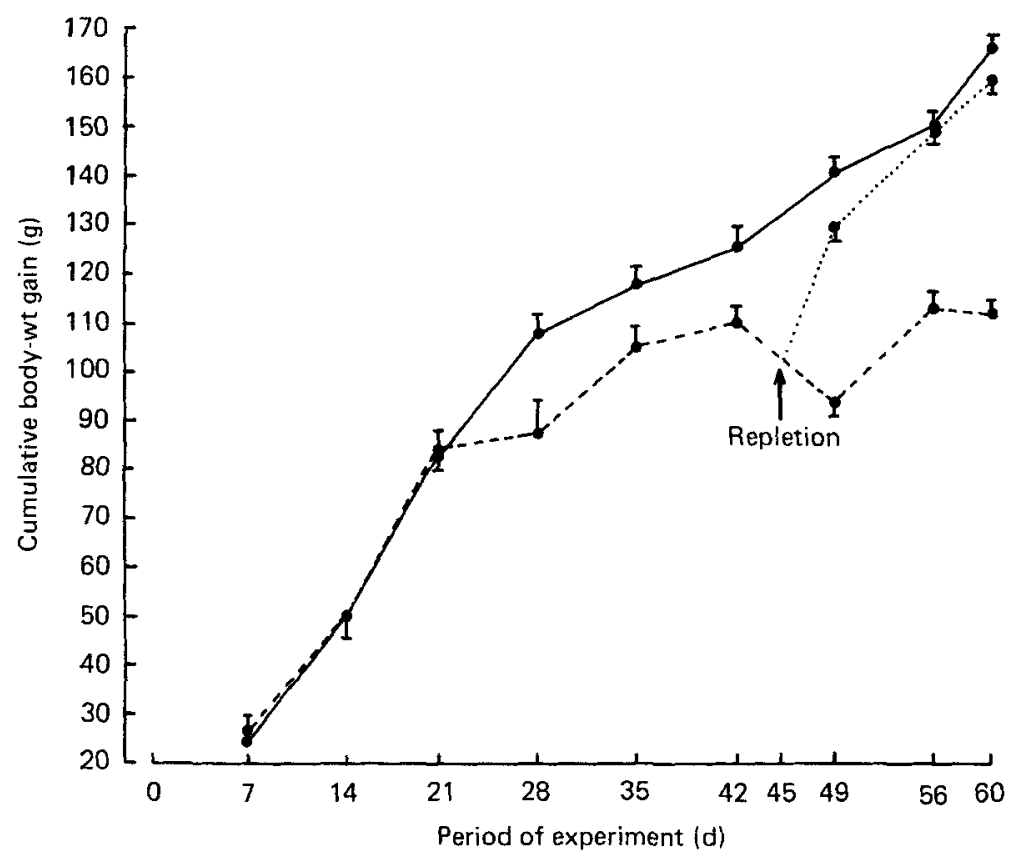

Fig. 2. Body-weight gain (g) of Zn-deficient (---), Zn-replete (. . .) and control (- - guinea-pigs. Values are means with their standard errors represented by vertical bars.

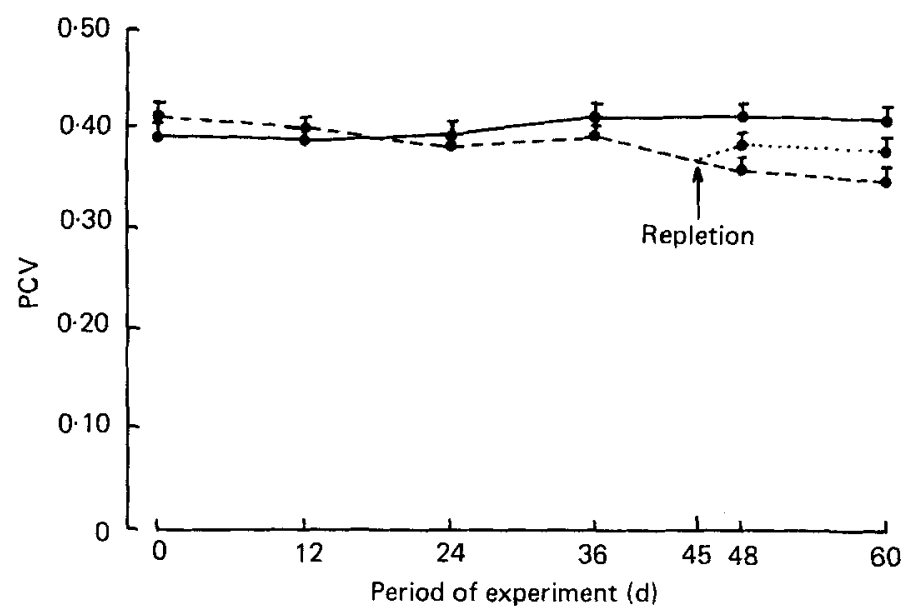

Fig. 3. Effect of zinc on packed cell volume (PCV) of Zn-deficient (---), Zn-replete (...) and control (-) guinea-pigs. Values are means with their standard errors represented by vertical bars.

\section{Clinical signs, growth and feeding response}

In guinea-pigs given diet $\mathrm{ZnD}$, no clinical sign was observed up to the 2 nd week of the experiment. During the $3 \mathrm{rd}$ week, the animals appeared listless and disinclined to move. Subsequently, scabby lesions appeared on the skin near the foot pads; there was mild alopecia and the animals were seen to lick the cages. None of the guinea-pigs in the control group showed any untoward clinical sign.

Average body-weight gains of each experimental group are shown in Fig. 2. A 


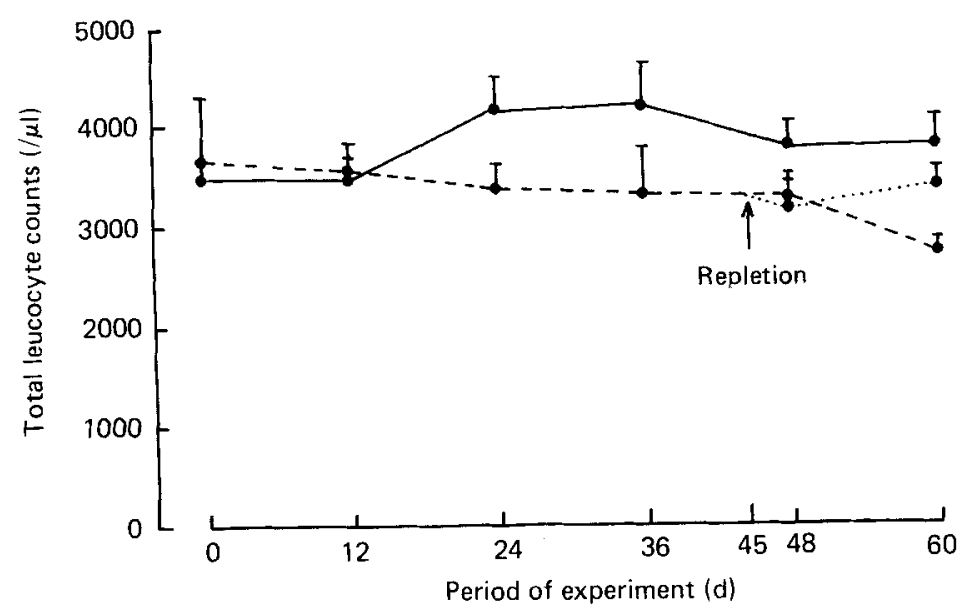

Fig. 4. Effect of zinc on total leucocyte counts of $\mathrm{Zn}$-deficient (--), $\mathrm{Zn}$-replete ( . . ), and control (--) guinea-pigs. Values are means with their standard errors represented by vertical bars.

statistically-significant decrease $(P<0 \cdot 05)$ in body-weight gain in group $\mathrm{ZnD}$ as compared with the control group was observed from week 4 onwards. This difference was highly significant $(P<0 \cdot 01)$ from week 6 of the experiment. At the end of the experiment, the average body-weight gain (g) of group $\mathrm{ZnD}$ was 112.8 (SE 2.00) while that of the control group was $167 \cdot 00$ (SE 2.24).

No significant difference in food consumption in the different groups of guinea-pigs was observed during the experiment. Average food intake was about $15-25 \mathrm{~g} / \mathrm{d}$ per guinea-pig.

Following $15 \mathrm{~d}$ of $\mathrm{Zn}$ supplementation, guinea-pigs given diet $\mathrm{ZnR}$ showed a marked improvement in clinical signs and body-weight gain.

\section{Haematological observations}

$P C V$. The mean PCV values for each of the experimental groups are shown in Fig. 3. The decrease in $\mathrm{PCV}$ in group $\mathrm{ZnD}$ as compared with the control group was statistically significant $(P<0.01)$ from day 48 onwards. Following $15 \mathrm{~d}$ of $\mathrm{Zn}$ supplementation, an increase in mean PCV values was observed in group $\mathrm{ZnR}$ when compared with values for group $\mathrm{ZnD}$.

$T L C$. Mean TLC values for each experimental group are shown in Fig. 4. The mean TLC of group $\mathrm{ZnD}$ decreased within $24 \mathrm{~d}$ of the experiment as compared with the controls but the difference was statistically significant $(P<0.01)$ on day 60 only. Following $15 \mathrm{~d}$ of $\mathrm{Zn}$ supplementaion, the mean TLC in group ZnR (3400 (SE 167.93)/ $\mu$ l) was higher than that of group $\mathrm{ZnD}(2710$ (SE 90.82)/ $\mu$ ) but was still less than that of the control group (3779 (SE $319 \cdot 00) / \mu \mathrm{l})$.

DLC and absolute leucocyte count. Mean DLC values for each experimental group are given in Table 1 and absolute values of lymphocytes and neutrophils, calculated on the basis of TLC and DLC, are shown in Fig. 5.

In group $\mathrm{ZnD}$, a continuous increase in mean percentage neutrophils and a decrease in mean percentage lymphocytes was observed from day 24 onwards. A statistically significant difference $(P<0.05)$ between the groups, however, was found from day 36 onwards.

From Fig. 5, it is clear that there was a continuous decrease in absolute lymphocyte counts of group $\mathrm{ZnD}$ from the start of the experiment, except on day 48 when it was relatively higher. Absolute neutrophil counts in group $\mathrm{ZnD}$ were similar at different stages of the experiment except on days 36 and 48 when values were relatively higher. In group $\mathrm{ZnR}$ 


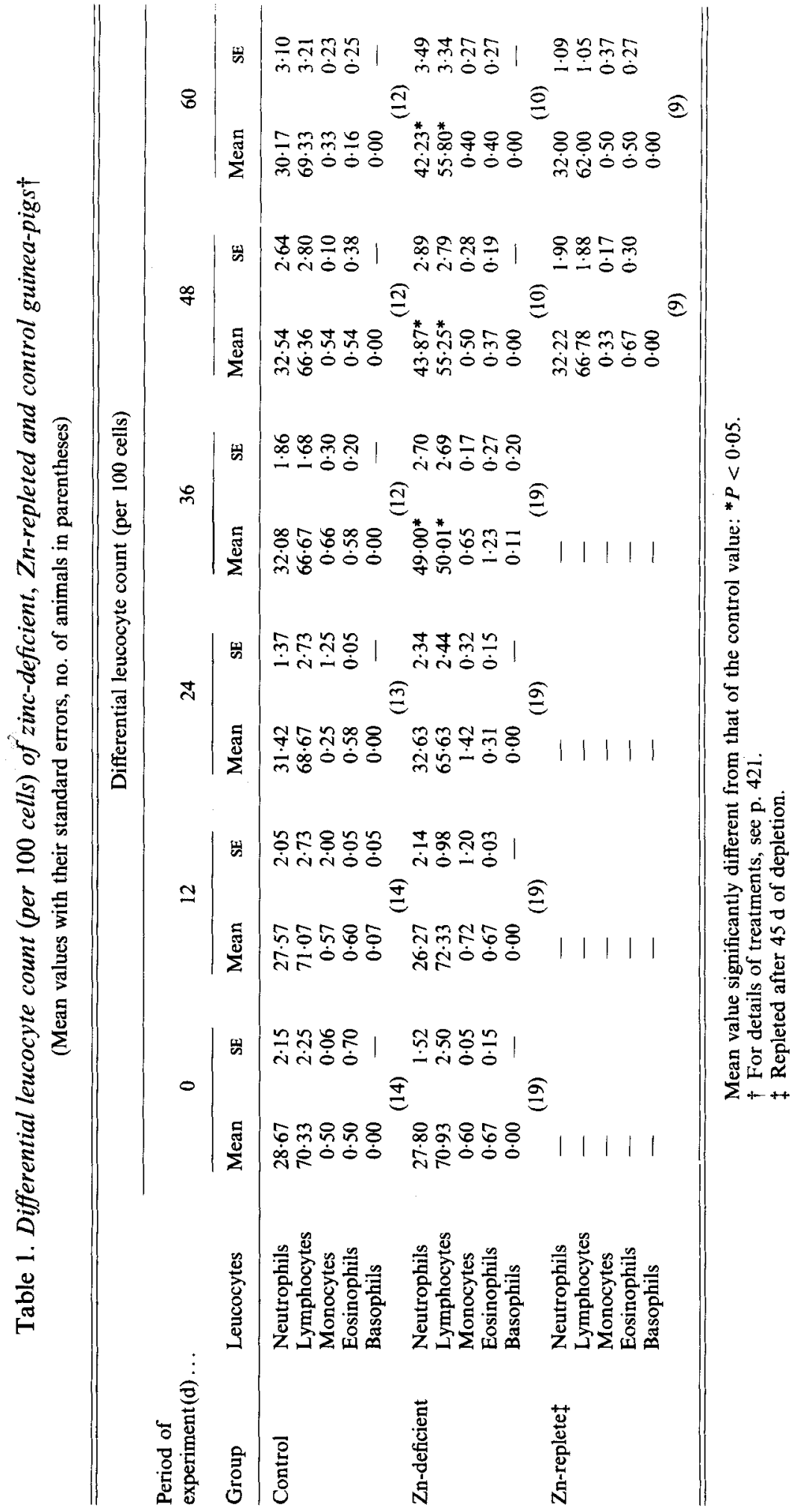




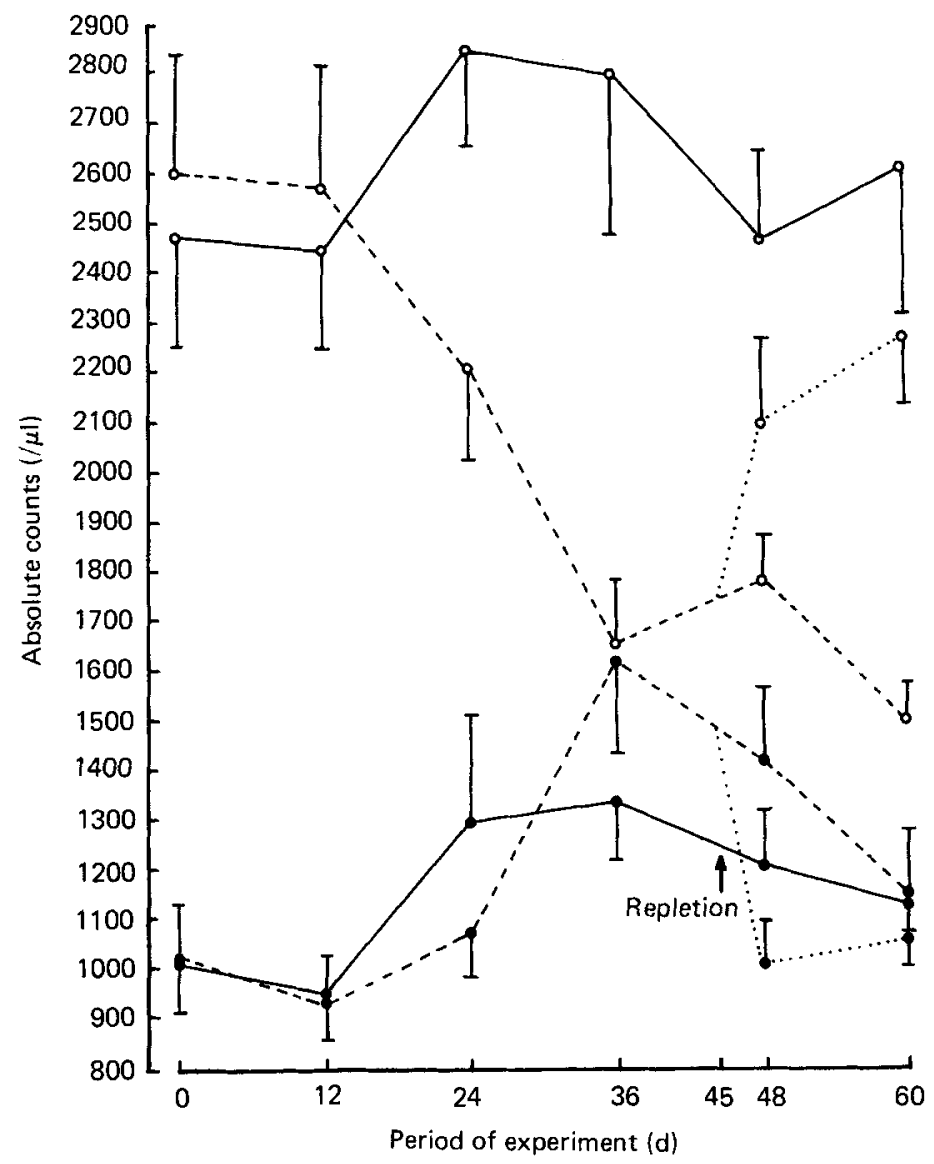

Fig. 5. Effect of zinc on absolute lymphocytes $(O)$ and neutrophils $(O)$ of $\mathrm{Zn}$-deficient (---), $\mathrm{Zn}$-replete $(\ldots)$ and control $(-)$ guinea-pigs. Values are means with their standard errors represented by vertical bars.

a marked improvement in percentage and absolute neutrophils counts and lymphocytes values was noticed within $3 \mathrm{~d}$ of repletion. There was no significant difference in monocyte, eosinophil and basophil counts between the three groups ( $\mathrm{ZnD}, \mathrm{ZnR}$ and controls) throughout the experiment.

\section{DISCUSSION}

$\mathrm{Zn}$ deficiency could be produced experimentally within $21 \mathrm{~d}$ in the guinea-pigs given diet $\mathrm{ZnD}$, as evidenced by clinical signs and the reduction in the serum $\mathrm{Zn}$ level. Clinical signs observed included listlessness, scabby lesions on the skin near foot pads, mild alopecia and licking habits. McBean et al. (1972), Alberts et al. (1977) and Gordon \& O'Dell (1983) also reported similar signs in guinea-pigs within about $20 \mathrm{~d}$ of feeding them with the $\mathrm{Zn}$-deficient diet.

A reduction in body-weight gain in group $\mathrm{ZnD}$ was observed from week 4 onwards. McBean et al. (1972) did not find any significant reduction in weight gains in guinea-pigs given a $\mathrm{Zn}$-deficient diet containing $1.2 \mathrm{mg} \mathrm{Zn} / \mathrm{kg}$ diet. Hsieh \& Navia (1980), however, reported a reduction in body-weight gain in $\mathrm{Zn}$-deficient guinea-pigs after 2 weeks on the 
experimental diet. This could be explained by their use of a diet containing less than $1 \mathrm{mg}$ $\mathrm{Zn} / \mathrm{kg}$ diet whereas, in the present study, the level of $\mathrm{Zn}$ in the diet was $1.25 \mathrm{mg} / \mathrm{kg}$. Growth retardation due to $\mathrm{Zn}$-deficiency might be due to a decrease in the activity of thymidine kinase (EC 2.7.1.21) (Prasad \& Oberleas, 1974) or DNA nucleotidyltransferase (EC 2.7.7.7) (Smith \& Gawthorne, 1975). $\mathrm{Zn}$ is known to play an important role in cell division directly, especially in the Gl phase; Zn deficiency may thus lead to decreased growth (Riordan, 1976).

No significant difference in food consumption in the present study was observed in guinea-pigs of the various experimental groups. More or less similar findings were reported by $\mathrm{McBean}$ et al. (1972) who found that food consumption of $\mathrm{Zn}$-deficient guinea-pigs was identical to that of the controls over the $20 \mathrm{~d}$ of their experiment. Gordon \& O'Dell (1983) reported that guinea-pigs weighing about $350 \mathrm{~g}$ when given a $\mathrm{Zn}$-deficient diet did not show any reduction in food consumption, whereas guinea-pigs weighing less than $200 \mathrm{~g}$ showed a reduction in food intake but, on the basis of metabolic body-weight, it was neither significantly nor consistently depressed.

A significant decrease in PCV in group $\mathrm{ZnD}$ was evident from $48 \mathrm{~d}$ onwards. One of the possible causes for the decrease in PCV as reported by many other workers (Grant \& Root, 1952; Gordon et al. 1968; Benjamin, 1978) may be testicular atrophy and degeneration, a consistent feature of $\mathrm{Zn}$ deficiency (Prasad \& Oberleas, 1976; Mason et al. 1982). Splenomegaly, as observed in $\mathrm{Zn}$ deficiency by Prasad (1980) in human patients and by Gupta (1984) in guinea-pigs, may also have attributed to this reduction since sequestration of erythrocytes in an enlarged spleen results in a fall in PCV (Hess et al. 1976). Hypothyroidism as observed in the Zn-deficient guinea-pigs (Gupta, 1984) may also have played a role in the reduction in PCV values, since Morley et al. (1980) reported that in rats, $\mathrm{Zn}$ deficiency resulted in decreased levels of triiodothyronine and thyroxine, the hormones responsible for decreased PCV (Grant \& Root, 1952; Tudhope \& Wilson, 1969; Benjamin, 1978). Gordon \& O’Dell (1983), during 18-d experimental studies in guinea-pigs, reported that $\mathrm{Zn}$ deficiency had no effect on PCV.

TLC in the present study decreased in group $\mathrm{ZnD}$ within $24 \mathrm{~d}$ of the experiment but the decrease was statistically significant $(P<0.01)$ on day 60 only. A significant increase in percentage neutrophils and decrease in percentage lymphocyte counts in group $\mathrm{ZnD}$ were evident from day 36 onwards. With regard to their absolute counts, a decrease in lymphocyte count was observed only for group $\mathrm{ZnD}$. The absolute neutrophil counts were similar throughout the experiment except on days 36 and 48 when the values were relatively higher. Since there was a decrease in absolute lymphocyte counts and almost no change in absolute neutrophil counts, it could be inferred that the decrease in TLC found in group $\mathrm{ZnD}$ was mainly due to the decrease in the absolute lymphocyte count. One of the reasons for lymphocytopenia observed in the present study may be hyperadrenocorticism. Depasquale-Jardieu \& Fraker (1979) reported that $\mathrm{Zn}$ deficiency caused an increase in plasma corticosterone level which in turn destroyed thymic lymphocytes. The splenomegaly observed (Gupta, 1984) might have also resulted in some degree of lymphocytopenia. Lymphocytopenia due to $\mathrm{Zn}$ deficiency has also been reported in rats (Macapinlac et al. 1966).

In group $\mathrm{ZnR}$, the serum $\mathrm{Zn}$ concentration increased rapidly within $3 \mathrm{~d}$ of repletion. Alleviation in clinical signs, partial resumption in body-weight gain and marked improvement in PCV and TLC were noticed. Complete recovery in percentage and absolute values of neutrophils and lymphocytes was noticed after $3 \mathrm{~d}$ of repletion. Our findings relating to $\mathrm{Zn}$ repletion, with respect to clinical manifestations, are similar to those of Quarterman \& Humphries (1983), who also reported rapid healing of all skin lesions and resumption of growth within $8 \mathrm{~d}$ of $\mathrm{Zn}$ supplementation ( $20 \mathrm{mg} \mathrm{Zn} / \mathrm{kg} \mathrm{diet}$ ) to $\mathrm{Zn}$-deficient guinea-pigs. 
R.P.G. acknowledges the award of Junior Research Fellowship by the Indian Council of Agricultural Research, New Delhi.

\section{REFERENCES}

Alberts, J. C., Lang, J. A., Reyes, P. S. \& Briggs, C. M. (1977). Journal of Nutrition 107, 1517-1527.

Benjamin, M. M. (1978). Outline of Veterinary Clinical Pathology. Ames: Iowa State University Press.

Depasquale-Jardieu, P. \& Fraker, P. J. (1979). Journal of Nutrition 109, 1847-1855.

Gordon, A. S., Zanjani, E. D. \& McLaurin, W. D. (1968). Proceedings of the Society for Experimental Biology and Medicine 129, 871-877.

Gordon, D. P. \& O'Dell, B. L. (1983). Journal of Nutrition 113, 239-245.

Grant, W. C. \& Root, W. S. (1952). Physiological Reviews 32, 449-498.

Gupta, R. P. (1984). Clinico-pathological studies on zinc deficiency in guinea-pigs. MVSc Thesis, Haryana Agricultural University, Hisar, India.

Hess, C. E., Ayers, C. R. \& Sandusky, W. R. (1976). Blood 47, 629-644.

Hsieh, H. S. \& Navia, J. M. (1980). Journal of Nutrition 110, 1581-1588.

Macapinlac, M. P., Pearson, W. N. \& Darby, W. J. (1966). In Zinc Metabolism, pp. 142-166 [A. S. Prasad, editor]. Springfield: J. Charles \& C. Thomas.

McBean, L. D., Smith, J. C. Jr \& Halsted, J. A. (1972). Proceedings of the Society for Experimental Biology and Medicine 140, 1207-1209.

Mason, K. E., Burns, W. A. \& Smith, J. C. Jr (1982). Journal of Nutrition 112, 1019-1028.

Morley, J. E., Gordon, J. \& Hershman, J. M. (1980). American Journal of Clinical Nutrition 33, 1767-1770.

Navia, J. M. \& Lopez, H. (1973). Laboratory Animal Science 23, 111-114.

Prasad, A. S. (1980). In Zinc in the Environment, part II, Health Effects, pp. 30-53 [J. O. Nariagu, editor]. New York: John Wiley and Sons.

Prasad, A. S. \& Oberleas, D. (1974). Journal of Laboratory and Clinical Medicine 83, 634-639.

Prasad, A. S. \& Oberleas, D. (1976). Trace Elements in Human Health and Disease, vol. 1. New York: Academic Press.

Quaterman, J. \& Humphries, W. R. (1983). Journal of Comparative Pathology 93, 261-270.

Riordan, J. P. (1976). Medical Clinics of North America 60, 661-674.

Schalm, O. W., Jain, N. C. \& Carroll, E. J. (1975). Veterinary Hematology. Philadelphia: Lea \& Febiger.

Smith, J. E. \& Gawthorne, J. M. (1975). In Trace Elements in Soil-Plant-Animal Systems, p. 243[D. J. D. Nicholas and A. R. Egan, editors]. New York: Academic Press.

Tudhope, G. R. \& Wilson, G. M. (1969). The Thyroid and the Blood. Springfield: J. Charles \& C. Thomas.

Underwood, E. J. (1977). Trace Elements in Human and Animal Nutrition. New York: Academic Press. 